\title{
Ultrastructural Dynamics of Transendothelial Migration of Lymphocytes Through High Endothelial Venules (HEVs) of the Mucosa Associated Peyer's Patches
}

\section{ERDAL BALCAN ${ }^{1}$ \\ SABIRE KARAÇALI ${ }^{2 *}$ \\ ${ }^{1}$ Celal Bayar University, Faculty of Arts and Science Molecular Biology Section, Department of Biology Muradiye Campus 45047 Manisa, Turkey \\ ${ }^{2}$ Ege University, Faculty of Science \\ Molecular Biology Section, Department of Biology 35100 Bornova - Izmir, Turkey ( ${ }^{\star}$ retired)}

\section{Correspondence:}

Assoc. Prof. Dr. Erdal Balcan

e-mail: erdal.balcan@cbu.edu.tr,

erdal.balcan@gmail.com

Keywords: Postcapillary venules, leukocyte extravasation, Peyer's patches
Abbreviations
HEV: $\quad$ High endothelial venule
ICAM-1: Intercellular adhesion molecule 1
VCAM-1: Vascular cell adhesion molecule 1
PECAM-1: Platelet endothelial cell adhesion molecule 1
VVO: Vesiculo-vacuolar organelle
LBRC: Lateral border recycling compartment

\begin{abstract}
Background and Purpose: Although the pivotal role of high endothelial venules (HEVs) in the migration of leukocytes from the blood into the secondary lymphoid parenchyma is well established, conflicting ideas concerning the cellular dynamics both of leukocytes and endothelial cells throughout the migratory processes have been present. Here we focused specifically on the cellular dynamics of HEV from Peyer's patches in an ultrastructural perspective.
\end{abstract}

Materials and Methods: In order to determine the microstructural organization of transendothelial migration we used conventional methods for transmission electron microscopy.

Results: Our results indicate that both lymphocytes and endothelial cells are highly active in the processes of transmigration steps, and a series of morphological and cellular alterations can occur depending upon their activity. Various types of cellular protrusions provide a direct contact between luminal lymphocytes and the endothelial cells at the initial phases of the migration. The endothelial protrusions subsequently embrace the lymphocytes and guide them into lymphoid stroma during the transcellular migration. Meanwhile, different sizes of vesicles show different cellular localizations according to their roles. The vesicles which are clustered near the lateral borders and the stand alone ones found only in the abluminal surfaces of endothelial cells might be involved in the paracellular migration. Concurrently, the other types of vesicles were smaller and appeared in the lateral border of the endothelial cells. Differ from the clustered and abluminally localized vesicles, they were closely related with plasma membranes.

Conclusions: These results indicated that not only adhesion molecules, but also cellular dynamics of leukocytes and endothelial cells regulate the leukocyte traffic into lymphoid stroma or vice versa.

\section{INTRODUCTION}

The trafficking of naïve lymphocytes to secondary lymphoid tissues 1 and/or organs is crucial for setting primary immune responses (1). Specialized post-capillary venules, so-called high endothelial venules (HEVs) are major sites for lymphocyte homing into the secondary lymphoid tissues except spleen. They are usually located in paracortical areas surrounding the B-cell follicles and show a characteristic histological morphology such as cuboidal endothelial cells $(2,3)$, thickened apical glycocalyx, and thickened basal lamina (4). The overall process
Received April 09, 2016

Revised July 26, 2016.

Accepted November 21, 2016. 
of lymphocyte migration into secondary lymphoid tissues has been well studied. It is now clear that the entering of naïve $\mathrm{B}$ and $\mathrm{T}$ cells to secondary lymphoid tissues is mediated by a series of adhesion and signaling events consisting of rolling, tethering, activation, arrest, and transendothelial migration (5). A large of number of adhesion molecules, including selectins, intercellular adhesion molecule 1 (ICAM-1), vascular cell adhesion molecule 1 (VCAM-1), platelet endothelial cell adhesion molecule 1 (PECAM-1), and several integrins and sialomucin families mutually interact at every step of leukocyte migration (6-11). During the transendothelial migration of leukocytes, two routes have been implicated: paracellular migration, through a gap between the adjacent endothelial cells, and transcellular migration, via a rift directly through an individual endothelial cell (12). Although the morphological changes in both leukocytes and endothelial cells have been well established during transendothelial migration, the question as to why leukocytes use two different routes in their migration has still not been elicited. The morphological basis for transendothelial migration of mouse mucosa associated lymphoid tissue-Peyer's patch HEVs has not been studied sufficiently except for a few excellent publications on guinea pigs and gerbils (13, 14). In the present work, we used transmission electron microscopy to look for ultrastructural features of mouse Peyer's patch HEVs that might elucidate the route of migrating lymphocytes.

\section{MATERIALS AND METHODS}

In order to examine lymphocyte migration in Peyer's patch HEVs, eight-week-old male vistar rats $(n=6)$ were sacrificed by cervical dislocation according to Animal Experimentation Ethics Committee of Ege University. The ilea were quickly removed from rats and fixed overnight with $2.5 \%$ glutaraldehyde- $2 \%$ paraformaldehyde at $+4{ }^{\circ} \mathrm{C}$ in $0.1 \mathrm{M}$ phosphate buffer $(\mathrm{pH} 7.4)$ and washed with $0.1 \mathrm{M}$ sodium cacodylate buffer $\left[\mathrm{Na}\left(\mathrm{CH}_{3}\right)_{2} \mathrm{AsO}_{2} \bullet\right.$ $\left.3 \mathrm{H}_{2} \mathrm{O}\right]$ ( $\mathrm{pH}$ 7.4). Subsequently, tissues were postfixed with $1 \%$ osmium tetraoxide $\left(\mathrm{OsO}_{4}\right)$ in sodium cacodylate buffer at $+4{ }^{\circ} \mathrm{C}$ for and dehydrated in graded ethanol series. The specimens were embedded in media (Epon 812, Serva) and the resin blocks were sectioned with an ultramicrotome (Reichart, Austria) equipped with glass knife. The thin sections were floated on double distilled water and transferred to copper grids. To stain the sections, uranyl acetate-lead citrate was used and finally sections were examined with a transmission electron microscope (Jeol 100 C, Japan).

\section{RESULTS AND DISCUSSION}

HEVs, which are organized microvessels especially for lymphocyte trafficking, are normally found in secondary lymphoid organs such as lymph nodes and Peyer's patches. During the chronically inflamed conditions, some of non-lymphoid tissues also show a vessel organization in a fashion similar to HEV structure $(15,16)$. It is a commonly accepted view that transmigration of lymphocyte into organized lymphoid architecture is a multi-staged event mediated by successive cellular interactions between lymphocytes and endothelial cells. Many types of trafficking molecules provide necessary information for these interactions $(17,18)$.

HEVs were localized in interfollicular region of Peyer's patches and characterized by a single layer of cuboidal endothelial cells, which are encircled by a regular, continuous, and thickened basal lamina containing pericytes, fibroblastic reticular cells, and extracellular matrix forming a perivascular sheath (Figure 1). Numerous cells, including erythrocytes, neutrophils, and lymphocytes can be seen in the HEV lumen. Each endothelial cell of HEV shows the thin cytoplasm surrounding the spherical and indented nucleus, contains Golgi apparatus, some mitochondria and rough endoplasmic reticulum cisternae

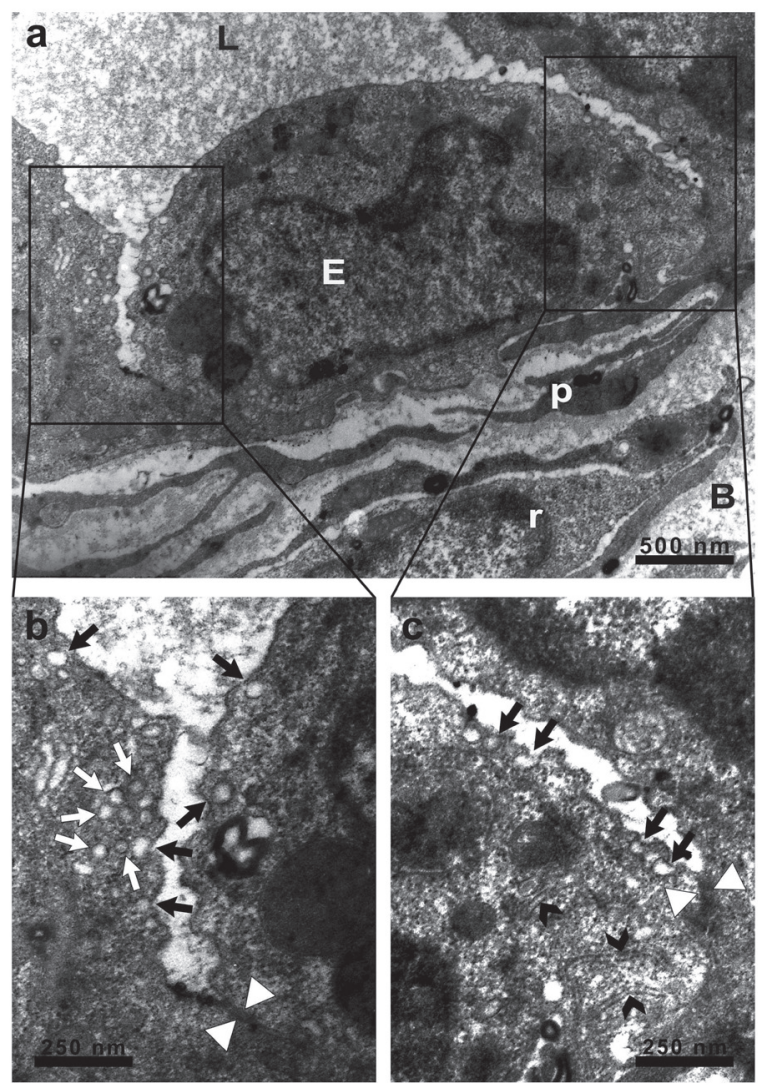

Figure 1. Electron micrographs of a "high" endothelial cell in the lumen of Peyer's patch HEV which shows an intended nucleus, Golgi stacks and mitochondria (a). The surrounding basal lamina (B) contains pericytes ( $p$ ) and pericyte-like fibroblsatic reticular cells (r) which embrace endothelial cells. VVOs (white arrows) and caveolae (dark arrows) occupy near the free borders andlor abluminal surfaces of endothelial cells $(b, c)$. Intercellular junctions (white arrowheads) and overlapped membrane processes (black arrowheads) can be seen between two individual endothelial cells $(b, c)$. L: lumen 

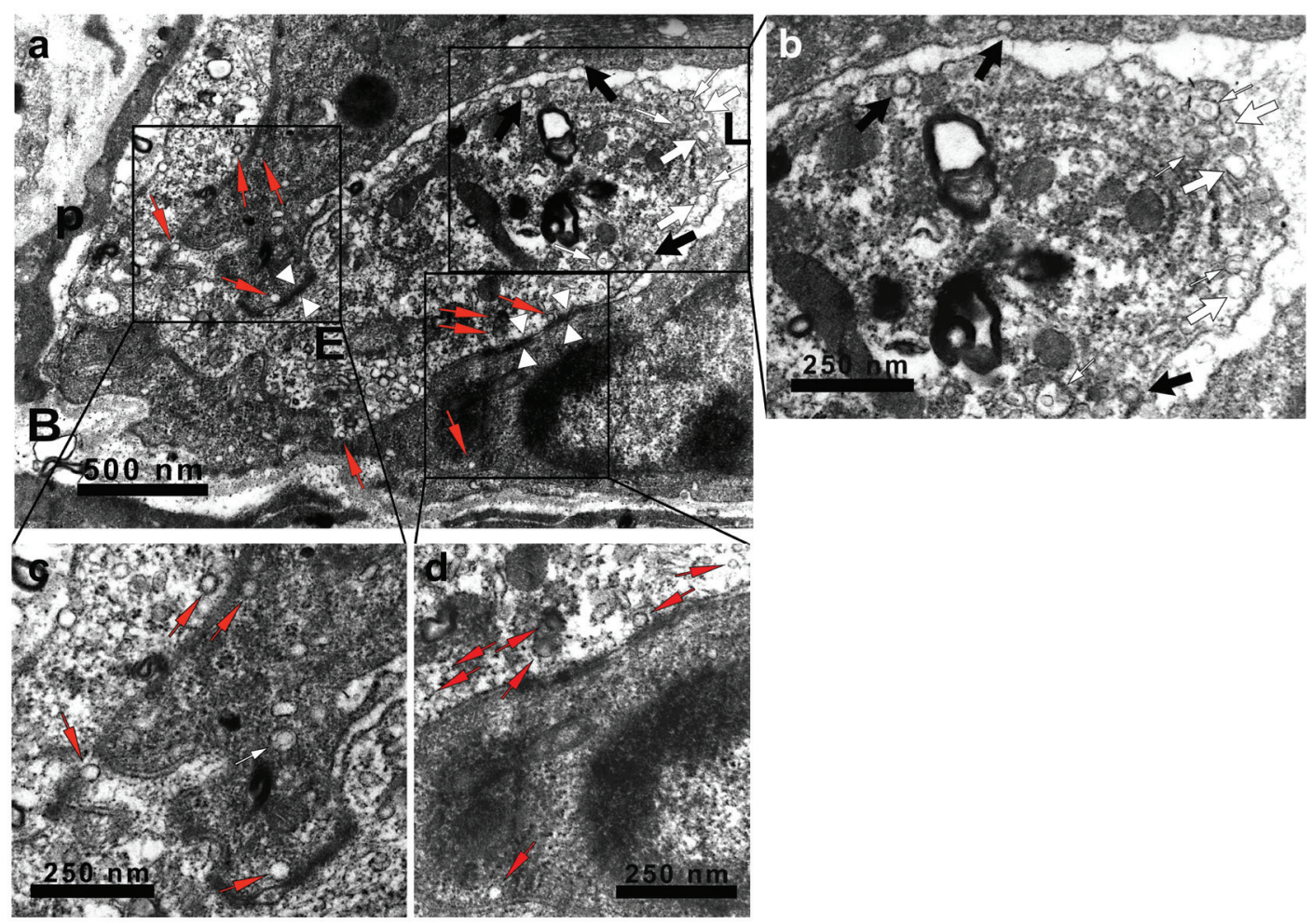

Figure 2. VVOs (white arrows) and caveolae (dark arrows) are populated near the abluminal surfaces of endothelial cells (a,b). Note the thin integuments closing luminal faces of caveolae $(b, d)$. Some of the VVOs exhibit electron-dense central discs (white thin arrows) (a-c). However, LBRC-like vesicles are located near the junctional borders of the endothelial cells (red arrows) (a,c,d). E: Endothelial cell, B: Basal layer, L: lumen, p: pericyte. White arrowheads indicate junctional connections between two individual endothelial cells.

(Figure 1). Overlapped membrane processes and desmosomal junctions were also observed among the endothelial cell borders of HEVs (Figure 1b,c).

HEV endothelial cells usually contain different sizes of vesicular structures called "vesiculo-vacuolar organelle (VVO)" (19). These vesicles create clusters near the lateral borders of endothelial cells and some of them vary in paleness, and they contain electron-dense central discs. Intriguingly, numerous vesicles were interconnected with each other and create a bunch, whereas some of the vesicular structures, which highly resemble caveolae, are separately merged into plasma membrane at only abluminal surface of the endothelial cell, and a thin integument closed them (Figure 2). In accordance with the present ultrastructural observations, previous studies have established that the membrane bound vesicles diminish the barrier function of endothelial cells and provide vascular permeability by means of a direct connection between cytoplasm and lumen (20). Therefore, VVOs and caveolae have been considered as fundamental membrane fusion elements for pore formation during the transcellular migration (21). On the other hand, the unique structural figures called "lateral border recycling compartment-LBRC" were distinct from VVOs $(22,23)$ and could function as a cellular storage for some of adhesion molecules including PECAM, CD99 and JAM-A
(24). It has been reported that LBRC is essential for paracellular and transcellular migration of lymphocytes in a microtubule-dependent manner (24). Our ultrastructural results showed that some vesicular organizations at the borders of resting endothelial cells are structurally similar to LBRCs (Figure 2a,c,d). These vesicular structures were much smaller than VVOs and close to plasma membrane.

However, they disappeared during the engulfment of emigrating lymphocytes, probably due to redirection of them to plasma membrane of active endothelial cell (22, 23). Because there is no specific marker for determining the LBRC, we are not sure whether these structures are LBRC. Even so, with these results it should be hypothesized that vesicular morphology is altered throughout the transendothelial migration according to their cargo and the activation status of the endothelial cell, thereby vesicular organelles can be potent regulators of migration events. Nevertheless, many important questions regarding the mechanism(s) of vesicular transformation and the purpose of recycling of LBRC have been unanswered at present $(25,26)$. Another important membrane dynamics of the lymphocytes and endothelial cells are cytoplasmic extensions: at the luminal surface, endothelial cells show various types of lamellopodium-like cellular protrusions in response to attacks of lymphocytes (Figure 3). We agree 


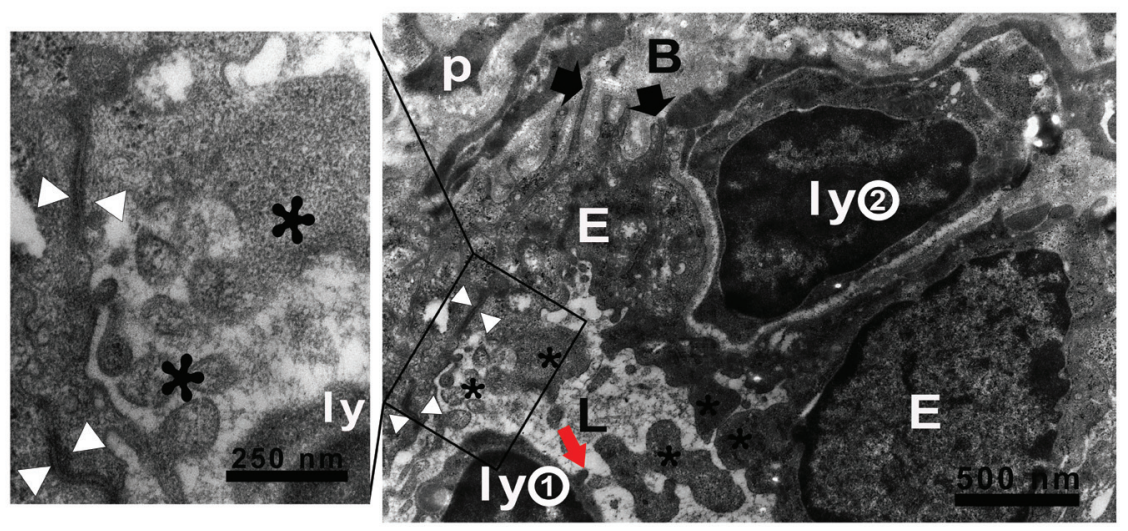

Figure 3. During the initial phases of transendothelial migration, active endothelial cells exhibit various types of cellular protrusions (asterisks). A luminal lymphocyte (ly 1) connects by a short projection to an endothelial protrusion (red arrow). However, a migrating lymphocyte (ly 2) loses its protrusions when it passes the HEV wall. Black arrows indicate finger-like endothelial extensions into basal layer (B). p: pericyte, white arrowheads represent cellular junctions between two adjacent endothelial cells (inset).

with the common view, these cellular projections are essential not only for cellular anchoring but also for extravasation of lymphocytes (27). Carman et al. (2007) showed lymphocyte invagine to human dermal and lung microvascular endothelial surfaces with podosomes (28). However, our findings have never shown podosomal structures inserting the endothelial cells of HEV. This difference is probably caused by differences in the activation status of endothelial cells between lymphoid tissue HEVs and other microvessels. Besides, numerous endothelial cells possess large finger-like projections progressing to the basal lamina (Figure 3).

\section{Transendothelial Migration: Paracellular or Transcellular Routes}

The migration of lymphocytes into lymphoid parenchyma includes a series of interactions between emigrating lymphocytes and endothelial cells, which are related with critical morphological and dynamic cellular changes, such as movement of plasma membranes. At this point, it should be noted that the adjacent endothelial cells display desmosomal junctions at their luminal interfaces. As a dynamic manifestation of intercellular junctions, various types and numbers of cellular processes including lamellipodia- and microvillus-like protrusions were ob-
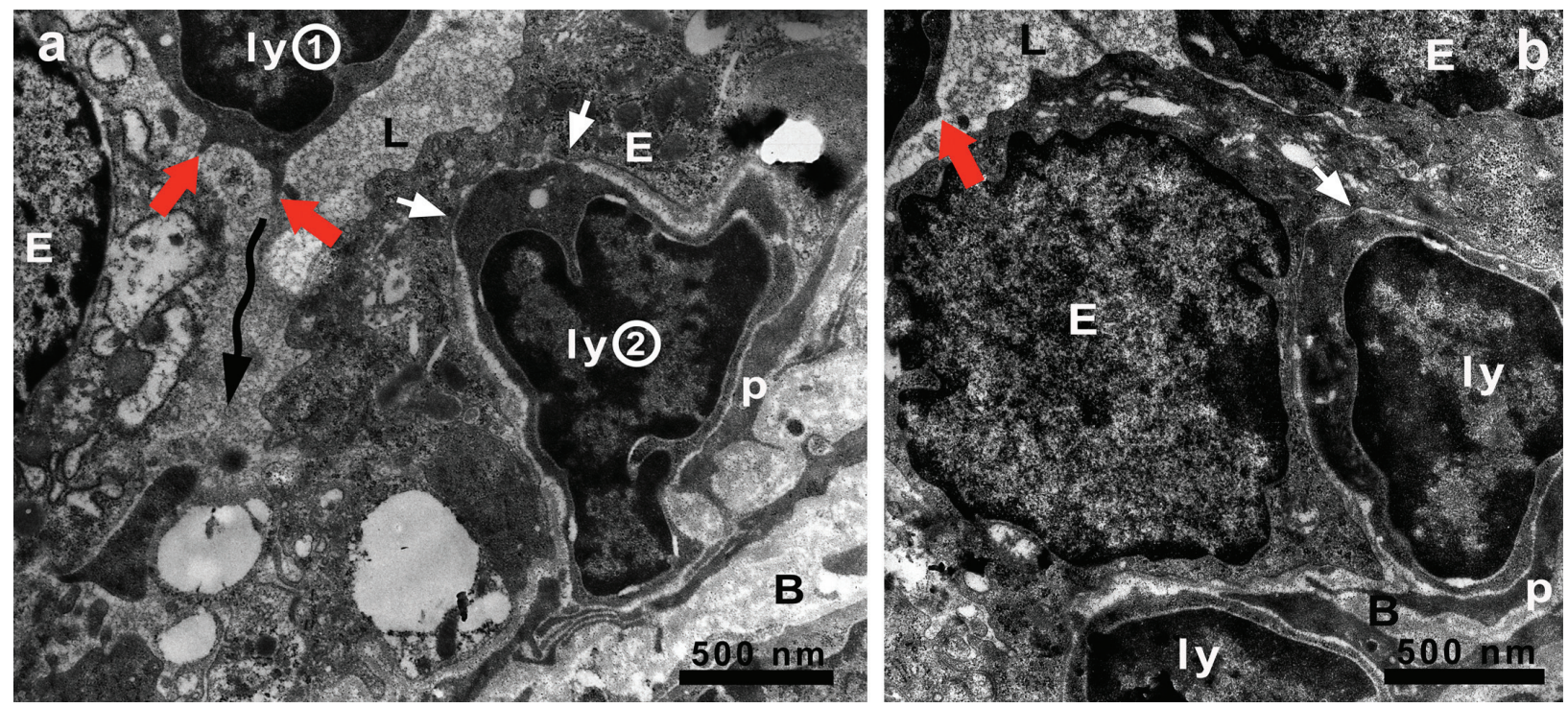

Figure 4. Two phases of paracellular transmigration. During the initial phase a lymphocyte (ly 1) exhibits small processes (red arrows) into a gap between two endothelial cells (waved arrow). Second lymphocyte (ly 2) embraced with an endothelial cell (E) during the subsequent phase of paracellular route (a). Note the cellular contact between endothelial cell and lymphocyte (white arrows) that appear in abluminal side (upstream surface) of the lymphocyte ( $a$ and b). L: lumen, B: basal layer, p: pericyte. 


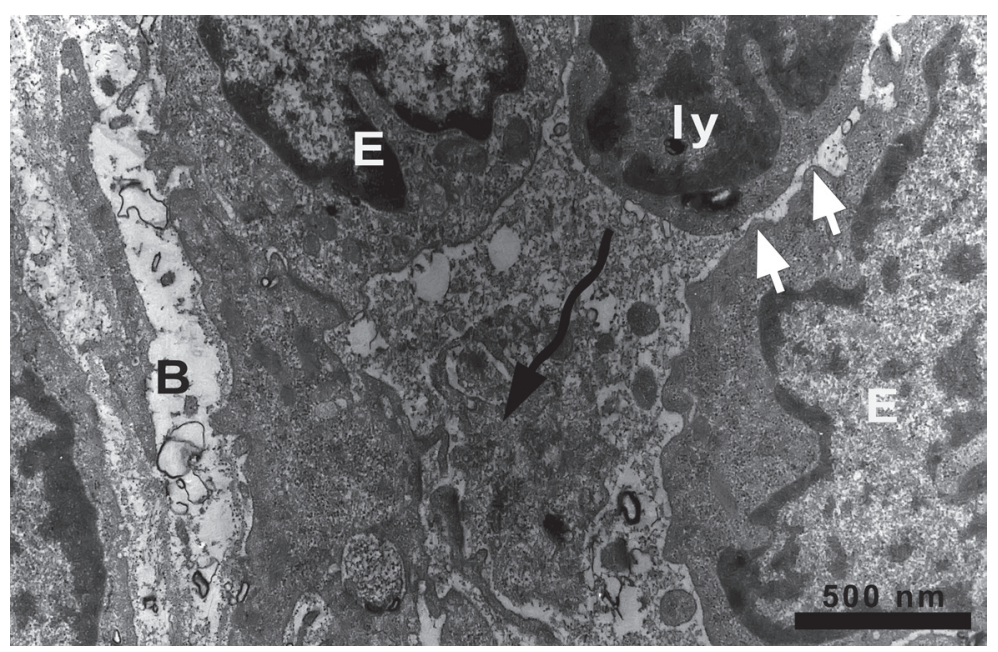

Figure 5. A lymphocyte (ly) shows close contacts with an adjacent endothelial cell (E) (white arrows) in the direction of its paracellular route (waved arrow). B: Basal layer.
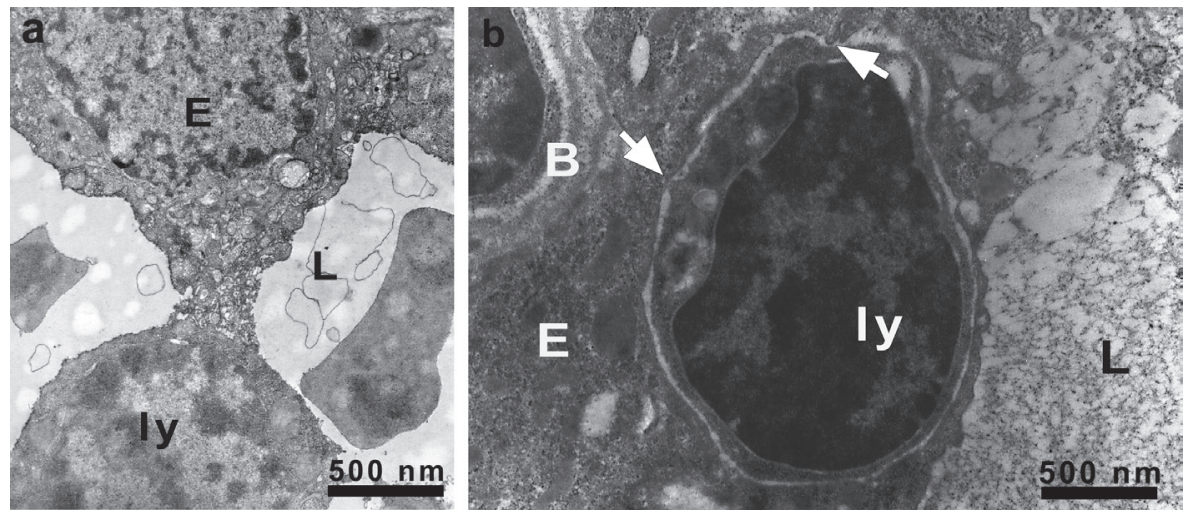

Figure 6. The initial steps of transcellular migration. A luminal lymphocyte (ly) and an endothelial cell (E) interact through their protrusions (a). Thereafter, lymphocyte completely embraced with endothelial cell. Note the close contacts between the lymphocyte and the endothelial cell, which only appeared in downstream surface of migrating lymphocytes (white arrows). For further steps of transcellular migration please see Figure 7. L: lumen, B: basal layer.

served both in emigrating lymphocytes and endothelial cells (Figure 3,4) $(29,30)$.

The engagement of lymphocytes to endothelial cells starts the paracellular or transcellular route and allows them to migrate via inter-endothelial crevices or intraendothelial patterns, respectively. Our electron microscopic observations showed that during the paracellular route, cellular contacts between migrating lymphocytes and endothelial cells coordinately change. In the initial phases of paracellular route, the only downstream surfaces of emigrating lymphocytes show close contacts with endothelial cells, whereas during the subsequent phases of the migratory flow, surfaces of forward movement became uncoupled (Figure 5). This might be related with increased vessel permeability to facilitate the migration. In some conditions, neutrophils might use thinned areas in order to shorten the route (31).
Towards the end of paracellular migration, endothelial cells embrace the emigrated lymphocytes and push them to basal layer (Figure 4b). The similar molecular events that orchestrate paracellular migration may also be implicated in transcellular route (32).

Unlike the paracellular migration, a notable morphological feature of transcellular route is the engulfment of lymphocytes by endothelial cells and subsequent formation of an intra-endothelial pattern (Figure 6) (22).

It was previously hypothesized that lymphoid podosomes initiate a transcellular channel (33). However, according to our ultrastructural data, endothelial cells completely embrace the migrating lymphocytes by their luminal protrusions, regarding to activation status of a given endothelial cell. These events occur immediately after the attachment of lymphocyte to endothelial cells and look like the steps of ,cell-in-cell” phenomenon (Fig- 


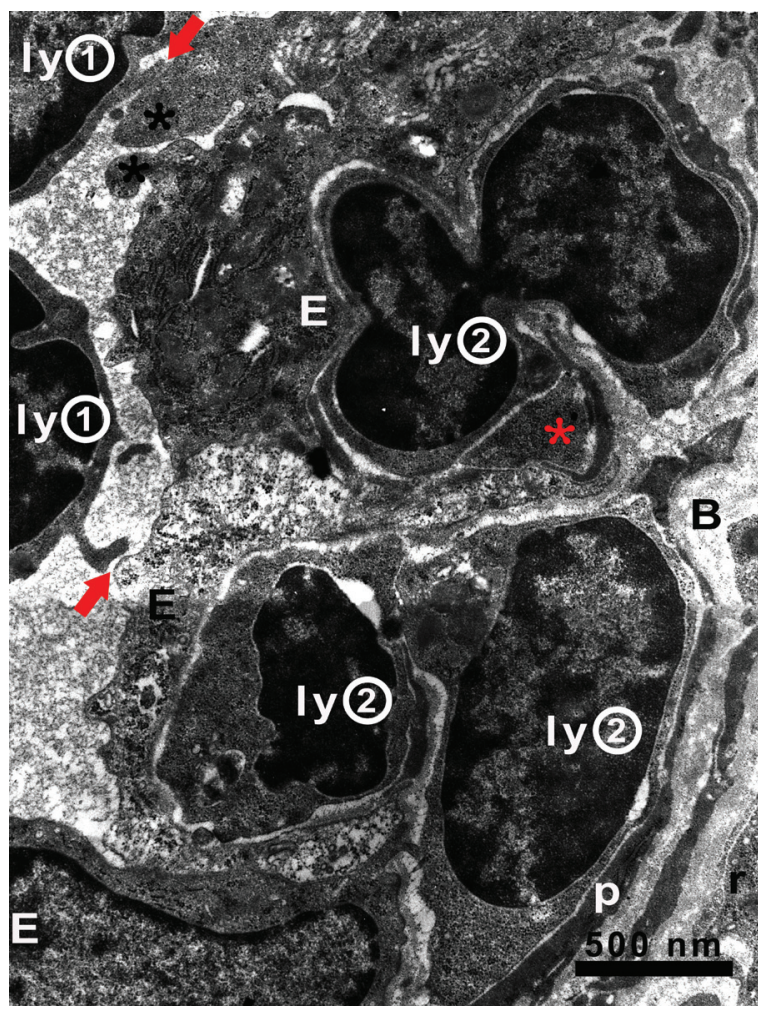

Figure 7. During the initial phase of transendothelial migration, luminal lymphocytes (ly 1) and endothelial cells (E) interact each other (red arrows). In the HEV wall, the other lymphocytes (ly 2) are exhibit subsequent phases of transcellular route. Black and red asterisks represent endothelial protrusions that interact and embrace the lymphocytes, respectively. B: basal layer, $p$ : pericyte, $r$ : reticular cell.

ure 6) (34). Increased rough endoplasmic reticulum cisternae and well developed Golgi stacks in endothelial cells with deep nuclear grooves in lymphocytes indicate that both endothelial cells and lymphocytes are highly active in the process of transcellular migration as reported previously (27). Importantly, junctions between intra-endothelial lymphocytes and surrounding endothelial cells were strongly decreased during the subsequent phases of the transcellular migration (Figure 7 ). These results are consistent with those of earlier reports $(35,36)$ and suggest that breakdown of the cellular contacts between intraendothelial lymphocytes and endothelial cells might accelerate the migration flow. At the end of transcellular route, lymphocytes perforate the endothelial cells and closely encountered with pericytes of basal lamina.

\section{CONCLUSION}

In conclusion, our ultrastructural observations refer to potential roles of cellular protrusions and vesicular formations as well as contacts in the course of transcellular migration. Although leukocyte extravasation has been studied for more than a century and numerous excellent researches have been manufactured (5), all of the on/off mechanisms underlying this cellular dynamic still remain highly fascinating and puzzling. For instance, what remains unknown is precisely how to control the attachment/detachment periods that changes at every step of the transmigratory process. We believe that to understand the cellular behavior of the lymphocytes and endothelial cells is very important as well as to determine the molecules involved in the process of leukocyte migration across endothelial cells, and we also believe that further researches will solve this enigmatic puzzle.

\section{REFERENCES}

1. von ANDRIAN UH, MACKAY CR 2000 T-cell function and migration. Two sides of the same coin. N Engl J Med 343 (14): 1020-1034. http://dx.doi.org/10.1056/nejm200010053431407

2. CLAESSON MH, JORGENSEN O, ROPKE C 1971 Light and electron microscopic studies of the paracortical post-capillary highendothelial venules. Z Zellforsch Mikrosk Anat 119 (2): 195-207. http://dx.doi.org/10.1007/bf00324521

3. ANDERSON ND, ANDERSON AO, WYLLIE RG 1975 Microvascular changes in lymph nodes draining skin allografts. $A m J$ Pathol 81 (1): 131-160

4. ANDERSON AO, SHAW S 1993 T cell adhesion to endothelium: the FRC conduit system and other anatomic and molecular features which facilitate the adhesion cascade in lymph node. Semin Immunol 5 (4): 271-282. http://dx.doi.org/10.1006/smim.1993.1031

5. GIRARD JP, MOUSSION C, FORSTER R 2012 HEVs, lymphatics and homeostatic immune cell trafficking in lymph nodes. Nat Rev Immunol 12 (11): 762-773. http://dx.doi.org/10.1038/nri3298

6. LAWRENCE MB, BERG EL, BUTCHER EC, SPRINGER TA 1995 Rolling of lymphocytes and neutrophils on peripheral node addressin and subsequent arrest on ICAM-1 in shear flow. Eur J Immunol 25 (4): 1025-1031.

http://dx.doi.org/10.1002/eji.1830250425

7. DWIR O, SHIMRON F, CHEN C, SINGER MS, ROSEN SD, ALON R 1998 GlyCAM-1 supports leukocyte rolling in flow: evidence for a greater dynamic stability of L-selectin rolling of lymphocytes than of neutrophils. Cell Adhes Commun 6 (4): 349370. http://dx.doi.org/10.3109/15419069809010793

8. FAVEEUW C, DI MAURO ME, PRICE AA, AGER A 2000 Roles of alpha(4) integrins/VCAM-1 and LFA-1/ICAM-1 in the binding and transendothelial migration of $\mathrm{T}$ lymphocytes and $\mathrm{T}$ lymphoblasts across high endothelial venules. Int Immunol 12 (3): 241-251. http://dx.doi.org/10.1093/intimm/12.3.241

9. SHAMRI R, GRABOVSKY V, GAUGUET JM, FEIGELSON $S$, MANEVICH E, KOLANUS W, ROBINSON MK, STAUNTON DE, von ANDRIAN UH, ALON R 2005 Lymphocyte arrest requires instantaneous induction of an extended LFA-1 conformation mediated by endothelium-bound chemokines. Nat Immunol 6 (5): 497-506. http://dx.doi.org/10.1038/ni1194

10. UMEMOTO E, TANAKA T, KANDA H, JIN S, TOHYA K, OTANI K, MATSUTANI T, MATSUMOTO M, EBISUNO Y, JANG MH, FUKUDA M, HIRATA T, MIYASAKA M 2006 Nepmucin, a novel HEV sialomucin, mediates L-selectin-dependent lymphocyte rolling and promotes lymphocyte adhesion under flow. J Exp Med 203 (6): 1603-1614. http://dx.doi.org/10.1084/jem.20052543 
11. MULLER WA 1995 Migration of leukocytes across the vascular intima molecules and mechanisms. Trends Cardiovasc Med 5 (1): 15-20. http://dx.doi.org/10.1016/1050-1738(94)00028-t

12. CARMAN CV 2009 Mechanisms for transcellular diapedesis: probing and pathfinding by 'invadosome-like protrusions'. J Cell Sci 122 (17): 3025-3035. http://dx.doi.org/10.1242/jcs.047522

13. AZZALI G, ARCARI ML, CALDARA GF 2008 The „mode“ of lymphocyte extravasation through HEV of Peyer's patches and its role in normal homing and inflammation. Microvasc Res 75 (2): 227-237. http://dx.doi.org/10.1016/j.mvr.2007.09.003

14. AZZALI G, ARCARI ML, CALDARA GF, VITALE M 2010 The „intraendothelial canalicular formation“: the route for lymphocyte diapedesis at the level of peripheral and mucosa-associated lymphoid tissue HEVs. Acta Biomed 81 (1): 5-20

15. FREEMONT AJ 1987 Molecules controlling lymphocyte-endothelial interactions in lymph nodes are produced in vessels of inflamed synovium. Ann Rheum Dis 46 (12): 924-928. http://dx.doi.org/10.1136/ard.46.12.924

16. SALMI M, GRANFORS K, MACDERMOTT R, JALKANEN S 1994 Aberrant binding of lamina propria lymphocytes to vascular endothelium in inflammatory bowel diseases. Gastroenterology 106 (3): 596-605. https://doi.org/10.1016/0016-5085(94)90691-2

17. MIYASAKA M, TANAKA T 2004 Lymphocyte trafficking across high endothelial venules: dogmas and enigmas. Nat Rev Immunol 4 (5): 360-370. http://dx.doi.org/10.1038/nri1354

18. MORA JR, von ANDRIAN UH 2006 T-cell homing specificity and plasticity: new concepts and future challenges. Trends Immunol 27 (5): 235-243. http://dx.doi.org/10.1016/j.it.2006.03.007

19. DVORAK AM, FENG D 2001 The vesiculo-vacuolar organelle (VVO). A new endothelial cell permeability organelle. J Histochem Cytochem 49 (4): 419-432. http://dx.doi.org/10.1177/002215540104900401

20. DVORAK AM, KOHN S, MORGAN ES, FOX P, NAGY JA, DVORAK HF 1996 The vesiculo-vacuolar organelle (VVO): a distinct endothelial cell structure that provides a transcellular pathway for macromolecular extravasation. J Leukoc Biol 59 (1): 100-115

21. FENG D, NAGY JA, DVORAK HF, DVORAK AM 2002 Ultrastructural studies define soluble macromolecular, particulate, and cellular transendothelial cell pathways in venules, lymphatic vessels, and tumor-associated microvessels in man and animals. $M i$ crosc Res Tech 57 (5): 289-326 http://dx.doi.org/10.1002/jemt.10087

22. MAMDOUH Z, CHEN X, PIERINI LM, MAXFIELD FR, MULLER WA 2003 Targeted recycling of PECAM from endothelial surface-connected compartments during diapedesis. Nature 421 (6924): 748-753. http://dx.doi.org/10.1038/nature01300

23. MAMDOUH Z, KREITZER GE, MULLER WA 2008 Leukocyte transmigration requires kinesin-mediated microtubule-dependent membrane trafficking from the lateral border recycling compartment. J Exp Med 205 (4): 951-966.

http://dx.doi.org/10.1084/jem.20072328
24. MAMDOUH Z, MIKHAILOV A, MULLER WA 2009 Transcellular migration of leukocytes is mediated by the endothelial lateral border recycling compartment. J Exp Med 206 (12): 27952808. http://dx.doi.org/10.1084/jem.20082745

25. MULLER WA 2009 Mechanisms of transendothelial migration of leukocytes. Circ Res 105 (3): 223-230.

http://dx.doi.org/10.1161/circresaha.109.200717

26. MULLER WA 2015 The regulation of transendothelial migration: new knowledge and new questions. Cardiovasc Res 107 (3): 310320. http://dx.doi.org/10.1093/cvr/cvv145

27. CARMAN CV, SPRINGER TA 2004 A transmigratory cup in leukocyte diapedesis both through individual vascular endothelial cells and between them. J Cell Biol 167 (2): 377-388. http://dx.doi.org/10.1083/jcb.200404129

28. CARMAN CV, SAGE PT, SCIUTO TE, de la FUENTE MA, GEHA RS, OCHS HD, DVORAK HF, DVORAK AM, SPRINGER TA 2007 Transcellular diapedesis is initiated by invasive podosomes. Immunity 26 (6): 784-797. http://dx.doi.org/10.1016/j.immuni.2007.04.015

29. CINAMON G, SHINDER V, SHAMRI R, ALON R 2004 Chemoattractant signals and beta 2 integrin occupancy at apical endothelial contacts combine with shear stress signals to promote transendothelial neutrophil migration. J Immunol 173 (12): 7282-7291. http://dx.doi.org/10.4049/jimmunol.173.12.7282

30. MILLAN J, HEWLETT L, GLYN M, TOOMRE D, CLARK P, RIDLEY AJ 2006 Lymphocyte transcellular migration occurs through recruitment of endothelial ICAM-1 to caveola- and Factin-rich domains. Nat Cell Biol 8 (2): 113-123. http://dx.doi.org/10.1038/ncb1356

31. FENG D, NAGY JA, PYNE K, DVORAK HF, DVORAK AM 1998 Neutrophils emigrate from venules by a transendothelial cell pathway in response to FMLP. J Exp Med 187 (6): 903-915. http://dx.doi.org/10.1084/jem.187.6.903

32. ENGELHARDT B, WOLBURG H 2004 Mini-review: Transendothelial migration of leukocytes: through the front door or around the side of the house? Eur J Immunol 34 (11): 2955-2963. http://dx.doi.org/10.1002/eji.200425327

33. FURIE MB, NAPRSTEK BL, SILVERSTEIN SC 1987 Migration of neutrophils across monolayers of cultured microvascular endothelial cells. An in vitro model of leucocyte extravasation. $J$ Cell Sci 88 (Pt 2): 161-175

34. OVERHOLTZER M, BRUGGE JS 2008 The cell biology of cellin-cell structures. Nat Rev Mol Cell Biol 9 (10): 796-809. http://dx.doi.org/10.1038/nrm2504

35. MULLER WA 2003 Leukocyte-endothelial-cell interactions in leukocyte transmigration and the inflammatory response. Trends Immunol 24 (6): 326-333. http://dx.doi.org/10.1016/s1471-4906(03)00117-0

36. AURRAND-LIONS M, JOHNSON-LEGER C, IMHOF BA 2002 The last molecular fortress in leukocyte trans-endothelial migration. Nat Immunol 3 (2): 116-118 http://dx.doi.org/10.1038/ni0202-116 